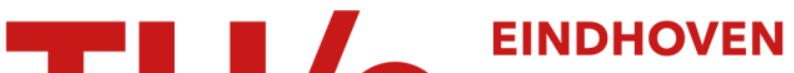 UNIVERSITY OF TECHNOLOGY
}

\section{Scale-up of microwave assisted flow synthesis by transient processing through monomode cavities in series}

\section{Citation for published version (APA):}

Patil, N. G., Benaskar, F., Rebrov, E., Meuldijk, J., Hulshof, L. A., Hessel, V., \& Schouten, J. C. (2014). Scale-up of microwave assisted flow synthesis by transient processing through monomode cavities in series. Organic Process Research \& Development, 18, 1400-1407. https://doi.org/10.1021/op500064k

DOI:

10.1021/op500064k

Document status and date:

Published: 01/01/2014

\section{Document Version:}

Publisher's PDF, also known as Version of Record (includes final page, issue and volume numbers)

\section{Please check the document version of this publication:}

- A submitted manuscript is the version of the article upon submission and before peer-review. There can be important differences between the submitted version and the official published version of record. People interested in the research are advised to contact the author for the final version of the publication, or visit the $\mathrm{DOI}$ to the publisher's website.

- The final author version and the galley proof are versions of the publication after peer review.

- The final published version features the final layout of the paper including the volume, issue and page numbers.

Link to publication

\section{General rights}

Copyright and moral rights for the publications made accessible in the public portal are retained by the authors and/or other copyright owners and it is a condition of accessing publications that users recognise and abide by the legal requirements associated with these rights.

- Users may download and print one copy of any publication from the public portal for the purpose of private study or research.

- You may not further distribute the material or use it for any profit-making activity or commercial gain

- You may freely distribute the URL identifying the publication in the public portal.

If the publication is distributed under the terms of Article 25fa of the Dutch Copyright Act, indicated by the "Taverne" license above, please follow below link for the End User Agreement:

www.tue.nl/taverne

Take down policy

If you believe that this document breaches copyright please contact us at:

openaccess@tue.nl

providing details and we will investigate your claim. 


\title{
Scale-up of Microwave Assisted Flow Synthesis by Transient Processing through Monomode Cavities in Series
}

\author{
Narendra G. Patil ${ }^{\dagger}$ Faysal Benaskar, ${ }^{\dagger}$ Evgeny V. Rebrov, ${ }^{\dagger}$ Jan Meuldijk, ${ }^{\dagger}$ Lubertus A. Hulshof, $^{\dagger}$ \\ Volker Hessel, ${ }^{\dagger}$ and Jaap C. Schouten $*^{\dagger}$ \\ ${ }^{\dagger}$ Laboratory of Chemical Reactor Engineering, Eindhoven University of Technology, P.O. Box 513, 5600 MB Eindhoven, The \\ Netherlands \\ ${ }^{\ddagger}$ School of Chemistry and Chemical Engineering, Queen’s University Belfast, Stranmillis Road, Belfast, BT9 5AG, United Kingdom
}

\begin{abstract}
A new scale-up concept for microwave assisted flow processing is presented where modular scale-up is achieved by implementing microwave cavities in series. The scale-up concept is demonstrated for case studies of a packed-bed reactor and a wall-coated tubular reactor. With known kinetics and reaction temperature, a packed-bed reactor gave a conversion of $99 \%$ with the highest production rate of $170 \mathrm{~kg}$ prod $/ \mathrm{kg}_{\text {cat }} \cdot \mathrm{h}$ for esterification of acetic acid and ethanol catalyzed by ion-exchange resin in 18 cavities. A similar approach for a multicomponent reaction of benzaldehyde, piperidine, and phenylacetylene catalyzed by a thin $\mathrm{Cu}$ film in a wall-coated tubular reactor gave $99 \%$ conversion with the highest production rate of $7740 \mathrm{~kg}_{\text {prod }} / \mathrm{kg}_{\text {cat }} \cdot \mathrm{h}$ in 28 cavities. In both cases, the pseudo first order reaction rate with respect to the limiting reactant yielded a typical rise in conversion and production rate. In a packed-bed reactor-heat exchanger operated at a temperature between 343 and $348 \mathrm{~K}$, the conversion in the esterification reaction increased from $22 \%$ to $88 \%$ when the number of cavities was increased from one to eight. The experimental conversions matched the predictions of a packed bed reactor model within $5 \%$. The production capacity in flow reactors, restricted to smaller sizes due to a limited microwave penetration depth and dominated mainly by the reaction kinetics, was increased by modular scale-up with implementation of the microwave multicavity assembly.
\end{abstract}

\section{INTRODUCTION}

Since the last two decades microwave heating has been studied as a promising tool for process intensification. ${ }^{1-4}$ The possibility of heating at the locus of the reaction, i.e., the catalyst surface, makes it a special intensification tool. ${ }^{5,6}$ Direct heating of the catalyst surface, where the reaction occurs, allows higher reaction rates at lower bulk liquid temperatures. This avoids not only large energy input but also excessive heating of the reactants which are sometimes lost due to coke formation. ${ }^{7,8}$ The inherently safe (immediate shut down of the energy supply) and efficient nature of the operation makes microwave heating attractive for industrial application. ${ }^{9,10}$ However, efficient microwave heating is severely limited by the penetration depth of the microwaves. ${ }^{11}$ The penetration depth, being typically in the millimeter range (e.g., $13 \mathrm{~mm}$ for water), limits uniform heating of the entire reaction mixture. This unpredictive nature of heating makes application for largescale batch processes difficult.

One of the options is to switch from batch operation to flow processing at the early stages in process development. However, replicating standardized batch procedures in continuous reactors not only leads to questionable underperformance but also jeopardizes the application of microwave heating in general. ${ }^{12-16}$ The idea of scaling very small batch volumes $(5 \mathrm{~mL})$ by replication in flow reactors (liters per $\mathrm{min}$ ) almost never works. $^{17,18}$ The reasons are simple. First, microwave heating is selective in nature, and often this characteristic is not explicitly understood for most of the case studies. Second, in almost all of the case studies, the process is initially developed in monomode type microwave cavities and then transferred to larger multimode microwave cavities for scaling up. However, our previous studies suggest that process performance is strongly dependent on the microwave equipment type. As a consequence, a specific microwave integrated reactor design is necessary for optimal performance., ${ }^{9,19}$

One of the suitable approaches for scaling microwave assisted flow processing is numbering-up. ${ }^{20,21}$ Scaling up by numberingup can be achieved by parallelization of tubular structured reactors with a channel diameter in the millimeter range. Multiple (parallelized) smaller reactors ensure high throughput while taking the penetration depth limitation into account. The throughput in the case of flow processing, however, is controlled by the kinetics of the conducted chemical reaction. More specifically, the kinetics of the reaction defines the flow rates through reactors needed for characterizing and optimizing the reactor performance at measurable conversions. This ultimately controls the production rate of a specific reactor type and hence the throughput of the process. In our previous work, we have already shown that, once optimized, the flow reactor concept can be scaled out by parallelization, leading to an increased throughput. ${ }^{21}$

Another possibility for scale-up is numbering-up microwave cavities in series. ${ }^{22}$ This approach, particularly with applicator type monomode cavities, permits optimization of the energy use in an individual cavity. ${ }^{5}$ Once optimized, the microwave cavity and the flow reactor can be placed in series to increase the productivity of the process. Additional improvement in the

Special Issue: Continuous Processes 14

Received: February 21, 2014

Published: July 17, 2014 
overall energy efficiency is obvious by using a single main waveguide (single magnetron), thus minimizing the multiple grid to applicator losses (conversion of electrical power into microwave power).

In this article, the above-mentioned concept of modular scale-up is presented where energy utilization and reactor performance are optimized at a cavity level and then scaled out by transient operation through cavities in series. The productivity increase with each additional cavity in series is determined for two different types of reactors, i.e., a packed-bed reactor and a wall-coated reactor. Two different chemical processes, an esterification of acetic acid and ethanol catalyzed by ion-exchange resin (in a packed-bed reactor) and a multicomponent reaction of benzaldehyde, piperidine, and phenylacetylene catalyzed by a thin $\mathrm{Cu}$ film (in a wall-coated tubular reactor) with previously quantified kinetics, ${ }^{5,14}$ are used for the estimation of the productivity. The theoretically predicted productivities are then validated for the former reaction in the case of a packed-bed reactor.

\section{RESULTS AND DISCUSSION}

An increase in production rate with each consecutive cavity was predicted for two cases, i.e., using a packed-bed reactor and using a wall-coated tubular reactor. The validation experiments were performed only for the esterification reaction case using a packed-bed reactor. The following subsections deal with a discussion on the obtained results in detail.

Packed-Bed Reactor. Conversion of acetic acid (limiting reactant) for the esterification reaction was calculated with the kinetic parameters (Table 1) and the reaction temperature of 348 K by using eq 7 (see section on Theoretical Determination of Productivity). Figure 1 (solid line) shows the dependence of

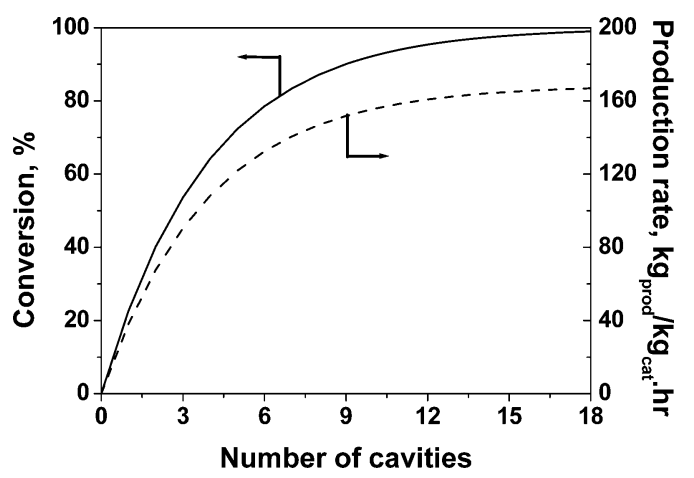

Figure 1. Predicted conversion of acetic acid (solid line) and production rate of ethyl acetate (dotted line) for the esterification reaction (Scheme 1) in a packed-bed reactor as a function of the number of cavities.

conversion on the number of individual cavities employed in series. The production rate of ethyl acetate (Figure 1, dotted line) was calculated from conversion using eq 11 (see section on Theoretical Determination of Productivity) assuming an equal amount of catalyst in each cavity (i.e., $W=3 \times 10^{-4} \mathrm{~kg}$ ).

A steep increase of the conversion as well as the production rate was observed for $0<N<8$ which later on flattened out for $N \geq 8$. This is typical for a pseudo-first-order dependency of the reaction rate on the concentration of limiting reactant (acetic acid). Theoretically, at around 18 cavities, the conversion reached almost $99 \%$, and the production rate at this conversion extrapolated to around $170 \mathrm{~kg}_{\text {prod }} / \mathrm{kg}_{\text {cat }} \cdot \mathrm{h}$.
Wall-Coated Tubular Reactor. Similarly, conversion of phenylacetylene for the multicomponent reaction (Scheme 2) was calculated using the known kinetic parameters (Table 2) and the catalyst surface temperature of $477.3 \mathrm{~K}$, through eq 10 (see section on Theoretical Determination of Productivity). Figure 2 shows the dependence of the conversion on the

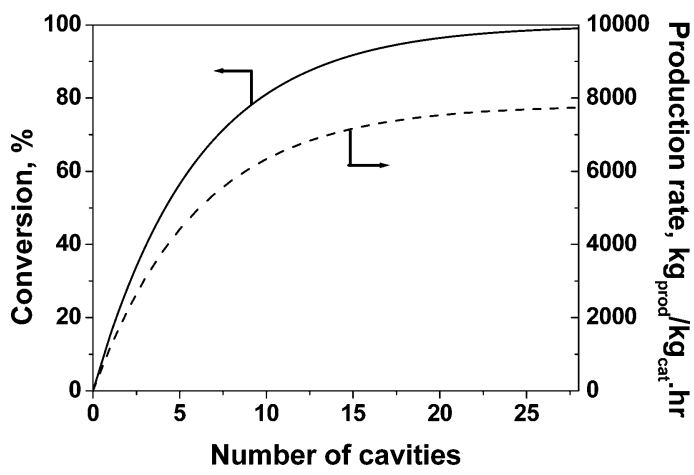

Figure 2. Predicted conversion of phenylacetylene (solid line) and the production rate of 1,3-diphenyl-2-propynyl piperidine (dotted) for the multi component reaction (Scheme 2) in a wall-coated tubular reactor as a function of the number of cavities.

number of cavities employed in series. The production rate was calculated by eq 11 (see section on Theoretical Determination of Productivity) based on the known catalyst amount needed per reactor (i.e., $W=2 \times 10^{-6} \mathrm{~kg} /$ reactor tube with six reactor tubes in parallel) in each cavity (Figure 2 , dotted line). Similar to the packed-bed reactor case, the multicomponent reaction is first order with respect to phenylacetylene in the wall-coated tubular reactor. Therefore, both the conversion as well as the production rate were seen to be increasing steeply at the beginning $(0<N<10)$ and then both flattened out in the latter part for $N \geq 10$.

At around 28 theoretical cavities, the conversion reached almost 99\%, and the production rate at this conversion extrapolated to around $7740 \mathrm{~kg}_{\text {prod }} / \mathrm{kg}_{\text {cat }} \cdot \mathrm{h}$. The production rate obtained for the wall-coated tubular reactor at a lower reaction mixture flow rate was a factor of 50 higher than the production rate obtained in the case of a packed-bed reactor for the esterification reaction. It should be noted that the flow rate of the multicomponent reaction mixture in the wall-coated reactor $\left(1.67 \times 10^{-7} \mathrm{~m}^{3} / \mathrm{s}\right)$ was a factor of 10 lower than for the esterification reaction in the packed-bed reactor $\left(1.67 \times 10^{-6}\right.$ $\left.\mathrm{m}^{3} / \mathrm{s}\right)$. This is majorly due to selective heating of the catalyst film which permits conversion calculation at high temperatures (100 K higher than the bulk) otherwise impossible to achieve with bulk liquid heating. ${ }^{22}$ Thus, catalyst activity increased by selective heating is a key issue for process intensification by using microwaves and milli-reactors.

It is important to note here that in both cases, i.e., a packed bed reactor and a wall-coated reactor, the theoretical conversion of $90 \%$ is achieved in 8 and 13 cavities in series, respectively. These are less than half the number of cavities needed to reach $99 \%$ conversion in both cases. Thus, it is more practical to exploit another ways such as increasing reactant concentration or reaction temperature to reach complete conversion. The approach of modular scale-up, i.e., utilization of cavities in series and independent operation through each consecutive cavity, provides such a possibility, while the approach of recycling ${ }^{23}$ having a conceptual similarity of 
conversion enhancement cannot provide such as a possibility. This particular feature makes the concept of modular scale-up more attractive.

Experimental Validation for the Packed-Bed Reactor. Next, the conversion and, consequently, the production rate were validated in the multicavity experiments for the case of the esterification reaction in a packed-bed reactor, i.e., reaction of acetic acid with excess of ethanol over a packed-bed of strong acid ion-exchange resin (Scheme 1). Figure 3 shows the steady

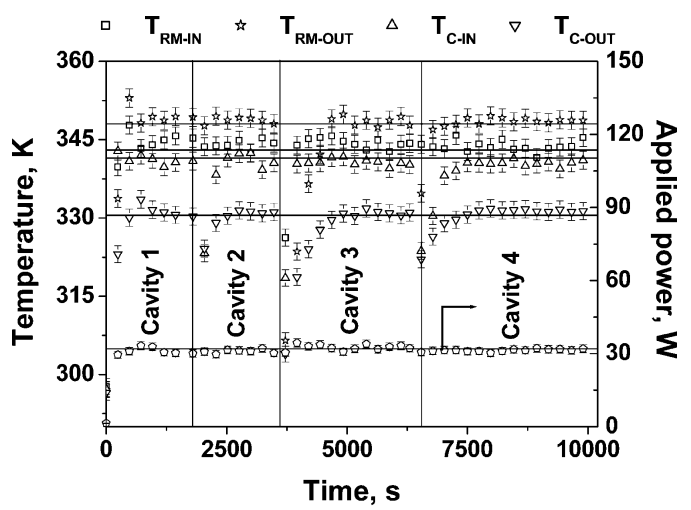

(a)

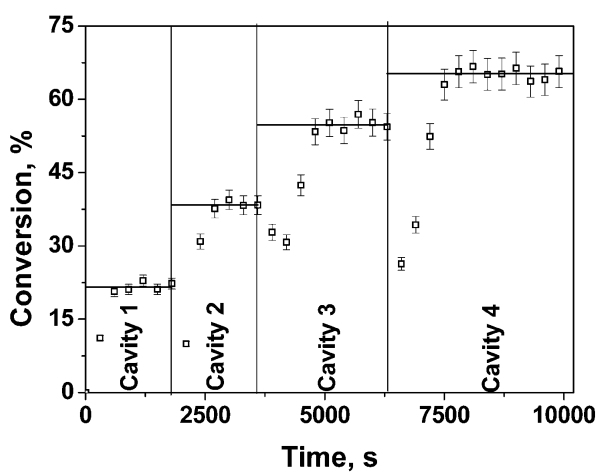

(b)

Figure 3. (a) Temperature-time history of a packed-bed reactor-heat exchanger assembly ( $\square$ : reactant inlet temperature, is: reactant outlet temperature, $\triangle$ : coolant inlet temperature, $\nabla$ : coolant outlet temperature, $\square$ : applied microwave power). (b) Conversion of acetic acid over time. Horizontal lines in both graphs demonstrate a steady state. Flow rates of the reaction mixture and the coolant were $1.67 \times$ $10^{-6}$ and $0.835 \times 10^{-6} \mathrm{~m}^{3} / \mathrm{s}$, respectively. RM: reaction mixture; C: coolant.

state temperature and the steady state conversion obtained in each consecutive cavity. The reaction mixture temperature was maintained between 343 and $348 \mathrm{~K}$ at an average applied microwave power of $32 \mathrm{~W}$ in each cavity (Figure 3 ). The steady state conversion increased logarithmically from $22 \%$ in the first cavity to $65 \%$ in the fourth cavity. The steady state conversions of $38 \%$ and $55 \%$ were obtained in the second and the third cavity, respectively.

Each time when the product stream of a stabilized cavity was connected as feed to the next cavity in series, the approach to a new steady state was longer. Similar to the conversion, the time required to reach a steady state increased linearly from $300 \mathrm{~s}$ in the first cavity to $1200 \mathrm{~s}$ in the fourth cavity. The time required to reach a steady state was 600 and $900 \mathrm{~s}$ for cavity 2 and cavity 3 , respectively. This was mainly due to shutdown of the setup (i.e., pumps and microwave power) before the product stream of the stabilized cavity was connected as feed stream to the next cavity in series. Thus, the time required to reach a steady state, although constant, added up linearly with each consecutive cavity. The thermal heat flux to the surrounding coolant flow amounted up to $20 \%$ of the total energy input to the packedbed reactor-heat exchanger assembly.

To see the influence of additional cavities in a series (from five to eight), the next set of experiments began with a reaction mixture composition corresponding to $65 \%$ conversion. Similar to previous observations, the reaction mixture temperature was maintained between 343 and $348 \mathrm{~K}$ at an average applied microwave power of $32 \mathrm{~W}$ in each cavity (Figure 4). However,

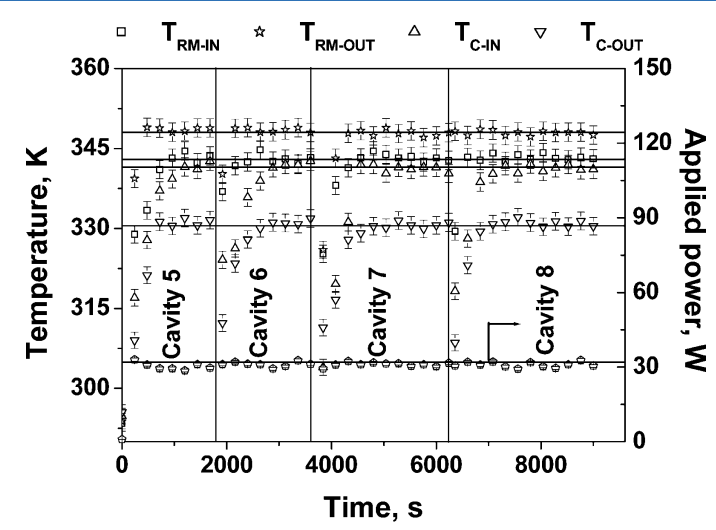

(a)

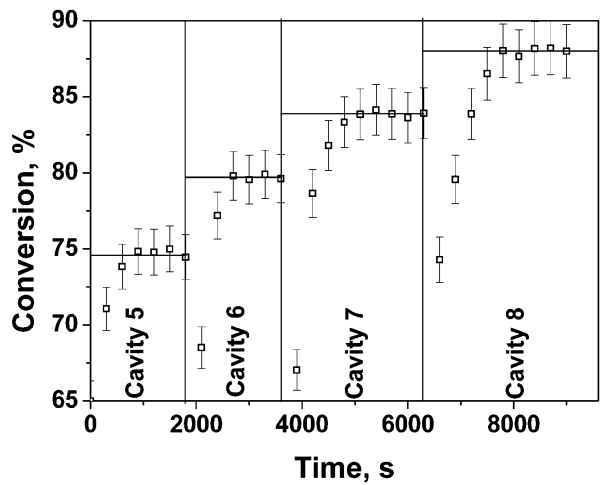

(b)

Figure 4. (a) Temperature-time history of a packed-bed reactor-heat exchanger assembly $(\square$ : reactant inlet temperature, 败: reactant outlet temperature, $\triangle$ : coolant inlet temperature, $\nabla$ : coolant outlet temperature, $\triangle$ : applied microwave power). (b) Conversion of acetic acid over time. Horizontal lines in both the graphs demonstrate steady state. Flow rates of the reaction mixture and the coolant were $1.67 \times$ $10^{-6}$ and $0.835 \times 10^{-6} \mathrm{~m}^{3} / \mathrm{s}$, respectively. RM: reaction mixture; C: coolant.

the increase of the steady state conversion with stepwise addition of cavities in series was lower in this case (Figure 4). It increased from $75 \%$ in the fifth cavity to $88 \%$ in the eighth cavity. The steady state conversions of $80 \%$ and $84 \%$ were obtained in the sixth and the seventh cavities, respectively. The production rate was then calculated for the obtained steady state conversion in each cavity by using eq 11 (see section on Theoretical Determination of Productivity). Finally, the experimental results for the conversion as well as for the production rate were compared with the predictions (Figure 5). 


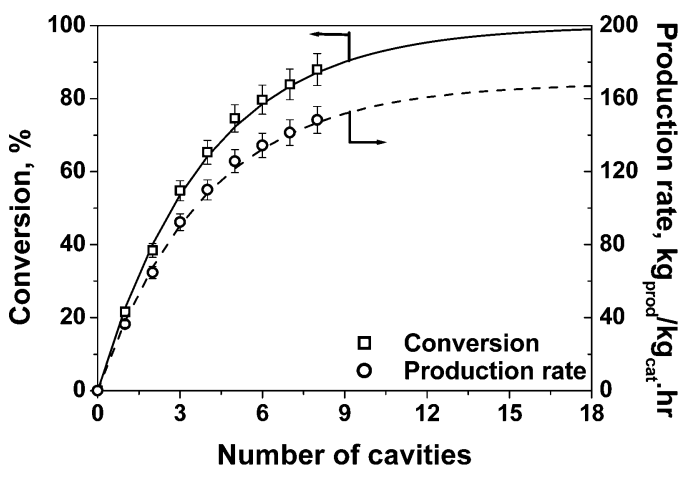

Figure 5. Experimental validation of the predicted conversion of acetic acid and the production rate of the ethyl acetate for the esterification reaction in the packed-bed reactor as a function of the number of cavities in series. Symbols: experimental results, lines: theoretical predictions. Model reaction: esterification of acetic acid and ethanol over a strong acid ion-exchange resin to produce ethyl acetate (Scheme 1).

The experimentally obtained conversions matched well with the model predictions (error $<5 \%$ ) for all number of cavities. Further validation by following the same strategy, i.e., beginning the next set of experiments at reaction mixture composition corresponding with $90 \%$ conversion, was not possible due to high experimental error which is comparable with the theoretically predicted change in the conversion (see prediction in Figure 5 for cavity number 9 onwards). The linearity in predictions based on global reaction kinetics and identical behavior of each additional cavity-reactor combination, however, does not require further validation. Therefore, it can be concluded that increasing the production capacity of the flow reactors is possible by increasing the number of microwave cavities in series. Each cavity must be independently tuned to the process requirements without disturbing the microwave field pattern either in neighboring cavities or in the main waveguide.

\section{CONCLUSIONS}

A concept of modular scale-up for microwave assisted flow processing has been demonstrated where utilization of cavities in series and transient operation through each consecutive cavity increased the production rate. Two cases, i.e., an esterification of acetic acid and ethanol catalyzed by ionexchange resin in a packed-bed reactor and a multicomponent reaction of benzadehyde, piperidine, and phenylacetylene catalyzed by $\mathrm{Cu}$-thin in a wall-coated tubular reactor were used to predict an increase in the conversion and, consequently, the production rate with the use of microwave cavities in series. For the case of esterification reaction in a packed-bed reactor, around 18 cavities in series gave a theoretical conversion of $99 \%$ with extrapolation to the production rate of $170 \mathrm{~kg}_{\text {prod }} / \mathrm{kg}_{\text {cat }} \cdot \mathrm{h}$. In contrast, the case of the multicomponent reaction in a wallcoated tubular reactor, a theoretical conversion of $99 \%$ with extrapolation to the production rate of $7740 \mathrm{~kg}_{\text {prod }} / \mathrm{kg}_{\text {cat }} \cdot \mathrm{h}$ was obtained in around 28 cavities. Validation experiments were performed for the case of esterification reaction in a packed-bed reactor-heat exchanger assembly at stable reaction temperatures between 343 and $348 \mathrm{~K}$. The steady state conversion rose from $22 \%$ in the first cavity to $88 \%$ in the eighth cavity used in series. The experimentally obtained results matched the predictions well within a $5 \%$ of error margin. Thus, an increase of production capacity in flow reactors proved to be possible by implementing microwave cavities in series. This was possible due to our microwave setup design which permitted the independent tuning of each cavity to process requirements without disturbing the microwave field pattern either in neighboring cavities or in the main waveguide. In conclusion, we have provided proof of concept for modular scale-up at a minimized grid to applicator losses by utilization of cavities in series over a main waveguide connected to single microwave generator.

\section{THEORETICAL DETERMINATION OF PRODUCTIVITY}

The productivity increase with each additional cavity in series is determined for two different types of catalytic reactors, i.e., a packed-bed reactor and a wall-coated reactor. The following subsections give the details of the steps followed for these calculations.

Esterification Reaction in a Packed-Bed Reactor. Esterification of ethanol and acetic acid to produce ethyl acetate over a packed-bed of strong acid ion-exchange resin (Purolite CT 275) is used as a model reaction (Scheme 1). The

Scheme 1. Esterification of acetic acid and ethanol over a solid ion-exchange catalyst to produce ethyl acetate

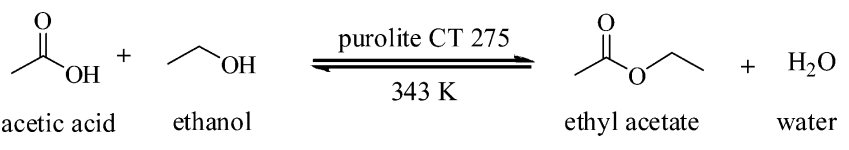

productivity increase with each consecutive cavity is predicted with known reaction kinetics as well as the dependence of the productivity on the reactor length, catalyst volume, and the reaction temperature. Since the catalyst in this case is confined in a packed-bed of predefined length, the differential form of a packed-bed reactor equation (eq 1 ) is solved.

$$
F_{V} \mathrm{dC}_{\mathrm{A}}=r_{\mathrm{A}}^{\prime}=k_{(T)}^{v} C_{\mathrm{A}} \mathrm{d} W
$$

Solving the differential equation (eq 1) leads to

$$
X=\left(1-\left(\exp \left(\frac{k^{V}}{F_{V}} W\right)\right)^{-1}\right) \times 100 \%
$$

Using eq 2, the increase in conversion with an increased amount of the catalyst $(W)$ can be predicted. The reaction rate constant $\left(k^{V}\right)$ is volumetric in nature, and it is dependent on the catalyst volume as well as on the reactor volume (eq 3 ).

$$
k^{V}=\frac{k_{\mathrm{obs}} V_{\mathrm{R}}}{V_{\mathrm{cat}}}\left[\frac{1}{s}\right]
$$

The observed reaction rate constant $\left(k_{\mathrm{obs}}\right)$ depends on the temperature through the Arrhenius equation (eq 4).

$$
k_{\text {obs }}(T)=k_{0} \mathrm{e}^{-E_{\mathrm{a}} / R T}
$$

The reactor volume is

$$
V_{\mathrm{R}}=\pi r^{2} l
$$

and the catalyst volume is

$$
V_{\text {cat }}=\frac{W}{\rho_{\text {cat }}}
$$


The length of the reactor $(l)$ and weight of the catalyst $(W)$ increased with each subsequent cavity in the series. The influence of increased reactor length and the catalyst weight, however, vanishes in the calculations of the volumetric reaction rate constant $\left(k^{V}\right.$, eq 3$)$. Therefore, the conversion and, consequently, the productivity increase could be mapped with each additional cavity in series for a packed-bed reactor by using the following equation:

$$
X=\left\{1-\left[\exp \left(\frac{k_{0} \mathrm{e}^{-E_{\mathrm{a}} / R T} V_{\mathrm{R}} W}{V_{\mathrm{cat}} F_{V}} N\right)\right]^{-1}\right\} \times 100 \%
$$

where $N$ is the number of cavities in series. Note that, for an equally sized reactor, $V_{\mathrm{R}} W / V_{\text {cat }} F_{V}$ is the same for each cavityreactor combination. The kinetic experiments to determine the activation energy $\left(E_{\mathrm{a}}\right)$ and the frequency factor $\left(k_{0}\right)$ are reported in our earlier publication. ${ }^{9}$

The values of parameters in eq 7 , collected in Table 1 , with an applied reaction temperature of $348 \mathrm{~K}$ are used to calculate the conversion $(X)$ as a function of the number of cavities $(N)$.

Table 1. Values of the parameters in eq 7 used for the calculation of the conversion and the production rate

parameter
$k_{0}$
$E_{\mathrm{a}}$
$r$
$l$
$W$
$\rho_{\text {cat }}$
$F_{V}$
$T$

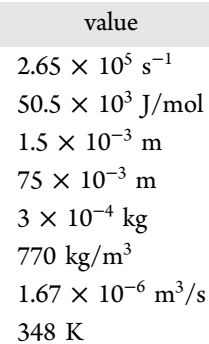

Multicomponent Reaction in a Wall-Coated Tubular Reactor. The multicomponent reaction of benzaldehyde, piperidine, and phenylacetylene to produce 1,3-diphenyl-2propynyl piperidine over a thin $\mathrm{Cu}$ film (Scheme 2) was used as the model reaction in the tubular reactor. The productivity increase in the wall-coated reactor with each consecutive cavity is predicted through known reaction kinetics and its dependence on the reactor length as well as the reaction temperature. Since the catalyst in this case is $\mathrm{Cu}$ deposited on the inner tube wall, the differential form of the plug flow reactor equation modified for the surface reaction (eq 8) is used.

$$
-F_{V} \mathrm{~d} C_{\mathrm{A}}=k^{\prime} a_{\mathrm{Cu}} C_{\mathrm{A}} \mathrm{d} x
$$

Solution of eq 8 for the surface reaction on the wall of a tubular reactor gives ${ }^{22}$

$$
\ln \left(\frac{1}{1-X}\right)=\frac{k_{0} \mathrm{e}^{-E_{\mathrm{a}} / R T}}{(1-\varepsilon)} \frac{d_{\mathrm{P}}}{6} \frac{a_{\mathrm{film}} \pi d_{\mathrm{R}} \delta l}{F_{V}}
$$

The only parameter that changes with each consecutive cavity in this case is the reactor length $(l)$. Therefore, the conversion and, consequently, the productivity are mapped with each additional cavity in series for a wall-coated reactor by using eq 10:

$$
X=\left\{1-\left[\exp \left(N \frac{k_{0} \mathrm{e}^{-E_{\mathrm{a}} / R T}}{(1-\varepsilon)} \frac{d_{\mathrm{P}}}{6} \frac{a_{\mathrm{film}} \pi d_{\mathrm{R}} \delta l}{F_{V}}\right)\right]^{-1}\right\}
$$

where $N$ is the number of cavities in series. The kinetic experiments to determine the activation energy $\left(E_{\mathrm{a}}\right)$ and the frequency factor $\left(k_{0}\right)$ are reported in our earlier publication. ${ }^{22}$

The values of the parameters in eq 10 , collected in Table 2, are used together with an applied catalyst surface temperature of $477.3 \mathrm{~K}$ for calculating the conversion $(X)$ as a function of the number of cavities $(N){ }^{22}$

Table 2. Values of the parameters in eq 10 used for the calculation of the conversion and the production rate

\begin{tabular}{ll} 
parameter & \multicolumn{1}{c}{ value } \\
$k_{0}$ & $1.42 \times 10^{3} \mathrm{~s}^{-1}$ \\
$E_{\mathrm{a}}$ & $51.7 \times 10^{3} \mathrm{~J} / \mathrm{mol}$ \\
$(1-\varepsilon)$ & $0.07 \mathrm{~m}^{3} \mathrm{cat}^{3} / \mathrm{m}_{\mathrm{R}}^{3}$ \\
$d_{\mathrm{p}}$ & $5 \times 10^{-5} \mathrm{~m}$ \\
$a_{\text {film }}$ & $8.92 \times 10^{6} \mathrm{~m}_{\mathrm{cat}}^{2} / \mathrm{m}^{3}{ }_{\mathrm{cat}}$ \\
$d_{\mathrm{R}}$ & $2 \times 10^{-3} \mathrm{~m}$ \\
$\delta$ & $3.5 \times 10^{-7} \mathrm{~m}$ \\
$l$ & $75 \times 10^{-3} \mathrm{~m}$ \\
$F_{V}$ & $1.7 \times 10^{-9} \mathrm{~m}^{3} / \mathrm{s}$ \\
$T$ & $477.3 \mathrm{~K}$
\end{tabular}

For both case studies, i.e., for the packed-bed reactor and the wall-coated tubular reactor, the conversion is translated into the production rate; see eq 11 .

$$
P=\frac{X C_{\mathrm{A}} F_{V} \mathrm{MW}}{W} \times 3600
$$

\section{EXPERIMENTAL SECTION}

Predictions of conversion and production rate with each consecutive cavity were validated for the ethyl acetate formation in a packed-bed reactor (Scheme 1). Figure 6 schematically illustrates the packed-bed reactor-heat exchanger assembly. The liquids, i.e., the reaction mixture and the coolant (toluene, anhydrous, 99.8 wt \%, Sigma-Aldrich), enter the microwave cavity first while flowing through the integrated

Scheme 2. Multicomponent reaction of benzaldehyde, piperidine, and phenylacetylene over a $\mathrm{Cu}$ thin film to produce 1,3 diphenyl-2-propynyl piperidine

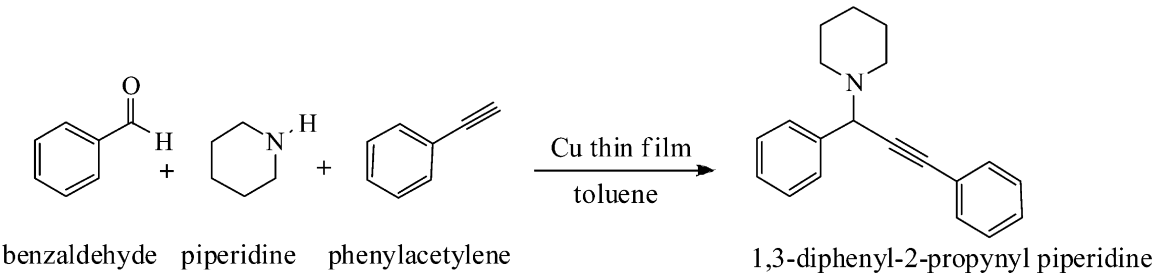




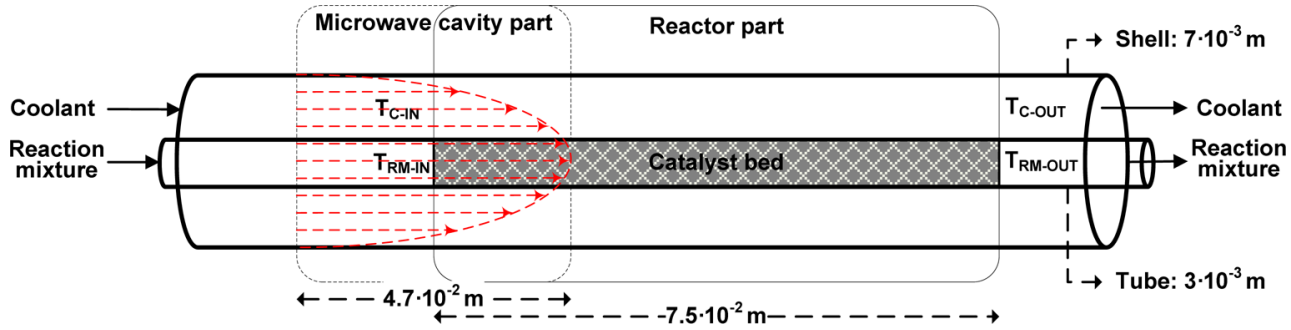

Figure 6. Schematic view of the packed-bed reactor-heat exchanger assembly used in the flow experiments of the esterification reaction. Red lines signify the microwave field pattern over the assembly.

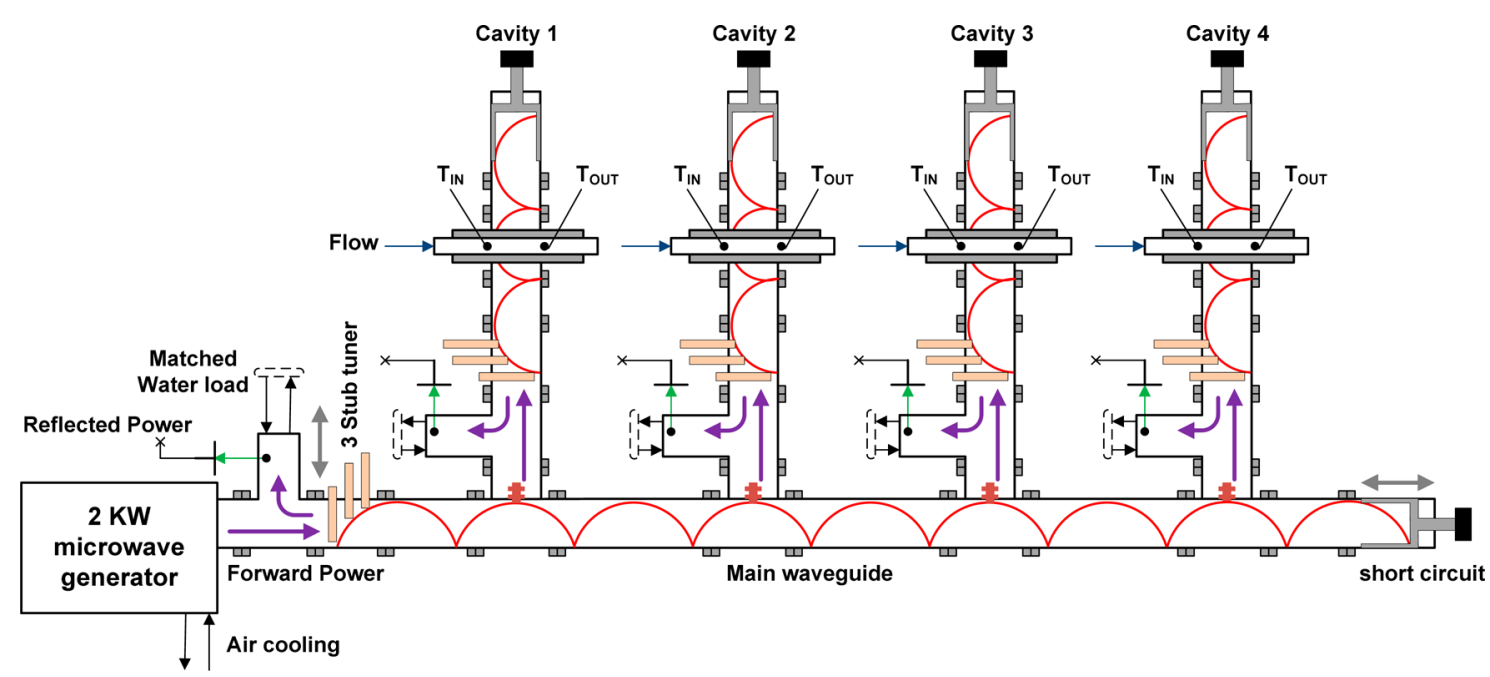

Figure 7. Schematic view of the microwave setup with an electric field pattern (red lines) in the setup. Arrows signify flow of energy (purple), signals (green), and liquids (blue), and movement of stub tuner, short circuit (grey). Actual load (reactor) opening diameter: $1.4 \times 10^{-2} \mathrm{~m}$. Manufacturer: Fricke and Mallah GMbH, Germany.

reactor-heat exchanger. Here, the reaction mixture is heated directly by the microwaves, and the excess of the microwave energy is transferred to the coolant by convective heat transfer. Co-current flow of the microwave transparent coolant is used to avoid overheating of the reaction mixture and to minimize the heat loss to the exterior of the microwave cavity by providing a heated jacket. In our earlier publication, optimization of the reactor-heat exchanger size and the length of the catalyst bed are discussed. ${ }^{9}$

Equipment. Microwave Setup. The microwave setup consists of a single mode microwave waveguide operating at a frequency of $2.45 \mathrm{GHz}$ with adjustable power settings up to 2 kW (Figure 7). Four parallel cavities are coaxially coupled with the main waveguide at equal distances to extract the same amount of microwave energy in each of the cavities. The concept of using a main waveguide with a single magnetron is to minimize the grid to applicator losses (conversion of electrical power into microwave power), while providing the possibility of a modular scale-up. ${ }^{24}$ Focusing of the resonating microwaves in the cavity as well as in the main waveguide is possible over the inserted reactor (packed-bed in this case, see Figure 6) by tuning the cavity with the help of short circuit and 3 stub tuner (Figure 7). Focusing of the microwaves allows getting the microwave field maxima on the reactor assembly as shown schematically in Figure 6. Focusing assures maximum microwave absorption by the reactor assembly and minimum losses to the dead load at the isolator of the cavity. The reflected power is recorded by using a detector diode on an isolator. This allowed calculation of the microwave power available in the cavity with an accuracy of $90 \%$. Process control and data acquisition were performed via the LABVIEW program.

Pumps. Two Gilson HPLC pumps (flow range: $8.33 \times 10^{-9}$ to $2.5 \times 10^{-6} \mathrm{~m}^{3} / \mathrm{s}$ ) were used to supply the reaction mixture and the coolant to the inner (reactor) tube and to the shell, of the reactor-heat exchanger assembly, respectively.

\section{EXPERIMENTAL PROCEDURES}

The heterogeneously catalyzed esterification (Scheme 1) of acetic acid (99.8\%, Sigma-Aldrich) and ethanol (99.8\%, SigmaAldrich) is conducted in a packed-bed reactor-heat exchanger assembly (Figure 6). 5-Fold excess of ethanol is used in order to increase the conversion for this equilibrium-limited reaction and to maintain a pseudo first-order reaction rate with respect to the acetic acid concentration. The reaction mixture and coolant are pumped through the assembly at the flow rates of $1.67 \times 10^{-6} \mathrm{~m}^{3} / \mathrm{s}$ and $8.35 \times 10^{-7} \mathrm{~m}^{3} / \mathrm{s}$, respectively. The catalyst, a strong acid ion-exchange resin (CT 275, Purolite) with an average particle diameter of $7.5 \times 10^{-4} \mathrm{~m}$, is dried for 2 days at room temperature before use. The catalyst bed is packed over a predefined length of $7.5 \times 10^{-2} \mathrm{~m}$ (Figure 6). The reaction mixture temperature is maintained between 343 and $348 \mathrm{~K}$ by tuning each cavity independently. Tuning of the cavity allowed controlling the amount of microwave power supplies to each cavity and, consequently, permitted control over the reaction mixture temperature. The unique feature of independent tuning of each cavity is possible due to our novel microwave setup design. 
The reaction mixture, flowing through the microwave cavity, gets heated to the desired reaction temperature and entered the catalyst bed for actual reaction before leaving the system towards the collection vessel. Samples are taken over time (every $5 \mathrm{~min}$ ) and analyzed by gas chromatography (GC) to determine the conversion. The samples for GC analysis are diluted with methyl isobutyl ketone (99.8\%, Sigma-Aldrich) at a dilution weight ratio of $1: 10$. Lowering the original concentration of the reaction components allowed precise determination of the concentrations. From the GC results, the conversion of acetic acid, the limiting reactant, is calculated over time. In multicavity experiments, the consecutive cavity is added only after achieving both steady state temperatures and conversion in the previous cavity. Thus, the experiment is started at the first cavity where a steady state is meanwhile achieved and then the outlets of the cavity are connected to the inlets of the second cavity. In a similar manner after achieving a steady state in second cavity, the outlets are connected to the third and then to the fourth cavity.

\section{AUTHOR INFORMATION}

\section{Corresponding Author}

*E-mail: j.c.schouten@tue.nl.

\section{Notes}

The authors declare no competing financial interest.

\section{ACKNOWLEDGMENTS}

Authors would like to acknowledge DSM Research, FrieslandCampina, IMM, LioniX, Milestone s.r.l., and the Dutch Technology Foundation STW (project MEMFiCS GSPT07974) for financial support.

\section{DEDICATION}

This paper is dedicated to the remembrance of one of the coauthors, Prof. Dr. L.A. (Bert) Hulshof, who passed away recently. In his work at DSM and at Eindhoven University of Technology, Professor Bert Hulshof made many original and creative contributions to the field of Fine Chemical Process Development. In his work Bert very successfully and systematically combined complex organic chemistry, catalysis and process technology. His systematic approach paved the way for efficient industrial scale production of many complex organic products. Bert's work on the application of microwave technology in chemical synthesis is groundbreaking. In this field he was a true pioneer.

\section{NOTATIONS}

\section{Symbol Description}

$a_{\text {film }} \quad$ surface area per unit volume of the copper film, $\mathrm{m}_{\text {cat }}^{2} /$ $\mathrm{m}^{3}$ cat

$a_{\mathrm{Cu}} \quad$ surface area per unit reactor length of the copper film, $\mathrm{m}^{2}{ }_{\text {cat }} / \mathrm{m}_{\mathrm{R}}$

$C_{\mathrm{A}}$ instantaneous concentration of limiting component $\mathrm{A}$, $\mathrm{mol} / \mathrm{m}_{\mathrm{R}}^{3}$

$d_{\mathrm{P}} \quad$ particle diameter of the powdered copper catalyst, $\mathrm{m}_{\text {cat }}$

$d_{\mathrm{R}} \quad$ reactor tube diameter, $\mathrm{m}_{\mathrm{R}}$

$E_{\mathrm{a}} \quad$ activation energy, $\mathrm{J} / \mathrm{mol}$

$F_{V} \quad$ volumetric flow rate, $\mathrm{m}^{3} / \mathrm{s}$

$k_{\text {obs }}$ observed reaction rate constant, $\mathrm{m}_{\text {cat }}^{3} / \mathrm{m}^{3} \cdot \mathrm{R}$

$k^{V} \quad$ volumetric reaction rate constant, $1 / \mathrm{s}$

$k^{\prime} \quad$ surface reaction rate constant, $\left(\mathrm{m}_{\mathrm{R}}^{3} / \mathrm{m}^{2}{ }_{\text {cat }} \cdot \mathrm{s}\right)$

$k_{0} \quad$ pre-exponential factor in Arrhenius equation, $\left(\mathrm{s}^{-1}\right)$ $l \quad$ reactor length, $\mathrm{m}_{\mathrm{R}}$

MW molecular weight, $\mathrm{g} / \mathrm{mol}$

$N \quad$ number of cavities

$P \quad$ production rate, $\mathrm{kg}_{\text {prod }} / \mathrm{kg}_{\text {cat }} \cdot \mathrm{h}$

$R \quad$ gas constant, $8.314 \mathrm{~J} / \mathrm{mol} \cdot \mathrm{K}$

$r \quad$ radius of the reactor, $\mathrm{m}_{\mathrm{R}}$

$r_{\mathrm{A}}$ reaction rate, $\mathrm{mol} / \mathrm{m}^{3}{ }_{\mathrm{R}} \cdot \mathrm{s}$

$T$ temperature, $\mathrm{K}$

$V_{\text {cat }} \quad$ catalyst volume, $\mathrm{m}_{\text {cat }}^{3}$

$V_{\mathrm{R}}$ reactor volume, $\mathrm{m}_{\mathrm{R}}^{3}$

$W \quad$ catalyst weight, $\mathrm{kg}_{\text {cat }}$

$x \quad$ differential reactor length, $\mathrm{m}_{\mathrm{R}}$

$X \quad$ conversion of phenylacetylene

\section{Greek Symbols}

$1-\varepsilon$ catalyst volume fraction

$\delta \quad$ catalyst film thickness, $\mathrm{m}$

$\rho_{\text {cat }} \quad$ catalyst density, $\mathrm{kg} / \mathrm{m}^{3}$

\section{REFERENCES}

(1) Gerven, T. Van.; Stankiewicz, A. Structure, energy, synergy, time The fundamentals of process intensification. Ind. Eng. Chem. Res. 2009, 48, 2465.

(2) Hessel, V. Novel Process Windows - Gate to Maximizing Process Intensification via Flow Chemistry. Chem. Eng. Technol. 2009, 32, 1655.

(3) Stankiewicz, A. On the Applications of Alternative Energy Forms and Transfer Mechanisms in Microprocessing Systems. Ind. Eng. Chem. Res. 2007, 46, 4232.

(4) Roberge, D. M.; Ducry, L.; Bieler, N.; Cretton, P.; Zimmermann, B. Microreactor Technology: A Revolution for the Fine Chemical and Pharmaceutical Industries? Chem. Eng. Technol. 2005, 28, 318.

(5) Shore, G.; Morin, S.; Organ, M. G. Catalysis in Capillaries by Pd Thin Films Using Microwave-Assisted Continuous-Flow Organic Synthesis (MACOS). Angew. Chem. 2006, 118, 2827.

(6) Shore, G.; Yoo, W.-J.; Li, C.-J.; Organ, M. G. Propargyl Amine Synthesis Catalysed by Gold and Copper Thin Films by Using Microwave-Assisted Continuous-Flow Organic Synthesis (MACOS). Chem.-Eur. J. 2010, 16, 126.

(7) He, P.; Haswell, S. J.; Fletcher, P. D. I. Efficiency, monitoring and control of microwave heating within a continuous flow capillary reactor. Sens. Actuators B 2005, 105, 516.

(8) Benaskar, F.; Hessel, V.; Krtschil, U.; Lob, P.; Stark, A. Intensification of the Capillary-Based Kolbe-Schmitt Synthesis from Resorcinol by Reactive Ionic Liquids, Microwave Heating, or a Combination Thereof. Org. Process Res. Dev. 2009, 13, 970.

(9) Patil, N. G.; Hermans, A. I. G.; Benaskar, F.; Rebrov, E. V.; Meuldijk, J.; Hulshof, L. A.; Hessel, V.; Schouten, J. C. Energy efficient and controlled flow processing under microwave heating by using a milli reactor-heat exchanger. AIChE J. 2012, 58, 3144.

(10) Roberge, D. M.; Gottsponer, M.; Eyholzer, M.; Kockmann, N. Industrial design, scale-up and use of microreactors. Chimica oggi. 2009, 27, 4.

(11) Damm, M.; Glasnov, N. T.; Kappe, C. O. Translating hightemperature microwave chemistry to scalable continuous flow processes. Org. Process Res. Dev. 2010, 14, 215.

(12) Moseley, J. D.; Lawton, S. J. Initial results from a commercial continuous flow microwave reactor for scale-up. Chem. Today 2007, $25,16$.

(13) Bergamelli, F.; Iannelli, M.; Marafie, J. A.; Moseley, J. D. A Commercial Continuous Flow Microwave Reactor Evaluated for ScaleUp. Org. Process Res. Dev. 2010, 14, 926.

(14) Bierbaum, R.; Nuchter, M.; Ondruschka, B. Microwave-assisted reaction engineering: Microwave apparatus at mini plant scale with online analysis. Chem. Eng. Technol. 2005, 28, 427.

(15) Leadbeater, N. E. Microwave heating as a tool for sustainable chemistry; CRC Press, Taylor and Francis Group: Boca Raton, FL, 2010. 
(16) Kremsner, J. M.; Stadler, A.; Kappe, C. O. The Scale-Up of microwave-Assisted Organic Synthesis. Top. Curr. Chem. 2006, 266, 233.

(17) Roberts, A. B.; Strauss, R. C. Towards rapid, "green” predictable microwave-assisted synthesis. Acc. Chem. Res. 2005, 38, 653.

(18) Chemat, F.; Esveld, E.; Poux, M.; Di-Martino, L. J. The role of selective heating in the microwave activation of heterogeneous catalysis reactions using a continuous microwave reactor. J. Microwave Power EE 1998, 33, 88.

(19) Patil, N. G.; Rebrov, E. V.; Esveld, E.; Eränen, K.; Benaskar, F.; Meuldijk, J.; Mikkola, J.-P.; Hessel, V.; Hulshof, L. A.; Murzin, D. Y.; Schouten, J. C. Effect of the load size on the efficiency of microwave heating under stop flow and continuous flow conditions. J. Microwave Power EE 2012, 46, 83.

(20) Comer, E.; Organ, M. G. A Microcapillary System for Simultaneous, Parallel Microwave-Assisted Synthesis. Chem.-Eur. J. 2005, 11, 7223.

(21) Patil, N. G.; Benaskar, F.; Rebrov, E. V.; Meuldijk, J.; Hulshof, L. A.; Hessel, V.; Schouten, J. C. Continuous multi-tubular milli-reactor with a $\mathrm{Cu}$ thin film for microwave assisted fine chemical synthesis. Ind. Eng. Chem. Res. 2012, 51, 14344.

(22) Matsuzawa, M.; Togashi, S.; Hasebe, S. Basic Examination of a Pilot Plant for Continuous Flow Microwave-Assisted Chemical Reaction Combined with Microreactors. J. Thermal Sci. Technol. 2011, 6, 69.

(23) Strauss, C. R. On Scale Up of Organic Reactions in Closed Vessel Microwave Systems. Org. Process Res. Dev. 2009, 13, 915.

(24) Patil, N. G.; Benaskar, F.; Rebrov, E. V.; Meuldijk, J.; Hulshof, L. A.; Hessel, V.; Schouten, J. C. Microwave setup design for continuous fine-chemicals synthesis. Chem. Eng. Technol. 2014, Submitted/in press. 